\title{
Association among Perceived Oral Health, General Health, Activity Limitation and Quality of Life in Korea Older Adults
}

\author{
Seungyoun Hong* \\ Department of Senior Industry, Kangnam University, South Korea
}

Received: February 28, 2018; Published: March 09, 2018

*Corresponding author: Seungyoun Hong, Department of Senior Industry, Kangnam University, Yongin, South Korea, Tel: 81-10-8799-4185;

Email: Yoni91@hotmail.com

\begin{abstract}
Background: The purpose of this research was to assess the association among self-rated oral health, general health, and quality of life (QOL) in Korean older adults.

Method: Data were analyzed from the 5th Korea National Health and Nutrition Examination Survey (KNHANES V, 2010) with 1,866 subjects, aged 60 or older. QOL was measured by EQ-5D (EuroQOl-5 Dimension). Self-rated oral health was queried in a health interview survey. Chi-square and hierarchical logistic regression analyses were conducted using IBM SPSS 23.0.

Results: More than $45 \%$ and $31 \%$ of the subjects rated their oral health and general health as poor, respectively. Subjects who were women $(\mathrm{t}=-0.24, \mathrm{p}<.05)$ and less educated $(\mathrm{p}<.05)$ were more likely to report poor perceived oral health. The correlation between oral and general health was weak $(\mathrm{rho}=0.14, \mathrm{p}<.001)$ but subjects perceived their general health very good and good had significantly better perceived oral health ( $\mathrm{F}=10.99, \mathrm{p}<.001)$. After controlling for confounders, subjects who had less difficulty in chewing (OR: $0.15,95 \% \mathrm{CI}: 0.13-0.20)$, better perceived health (OR: 0.47, 95\% CI: 0.25-0.90) and no depressive symptom (OR: 0.69, 95\% CI: 0.50-0.97) faced less perceived oral health difficulties than those who had chewing difficulties, worse perceived health and with depressive symptom.
\end{abstract}

Conclusion: In conclusion, self-rated health, general health, and quality of life were associated with each other in older adults. It is proposed that oral health, general health, and quality of life should be regarded as a holistic approach in the elderly population.

Keywords: Perceiver oral health; Activity limitation; QOL; Olders

\section{Introduction}

As the rapid aging of the population involves an increase in the prevalence of oral disease, researchers have become increasingly interested in the oral health of older people and its association of quality of life. Previous research demonstrated that substantial proportion of older adults and elderly population experience problem in chewing, pain, difficulties in eating, and difficulties in social relationship associated with conditions of oral disorders [1-3]. Dry mouth and the diminished number of teeth result in impaired food and beverage intake, which further undermine a person's quality of life [4-6]. Oral health is also has been proved so with many diseases such as diabetes, cardiovascular disease [7]. It has been stated that self-rated oral health status is the critical element toward a better quality of life [8].
Since the perception of oral health is considered to encompass both physical and psychological dimensions, it is commonly used in several studies to plan and monitor health services and in promoting oral health. Poor oral health may constitute an additional burden that causes further decrements in the general well-being and quality of life of older adults. Several researchers have evaluated the extent of the relationship between self-rated oral health and quality of life [9-11] and general health. To date, however, relatively fewer studies have addressed the relationship between self-rated health and self-rated oral health in older adults with the National dataset in Asia. We were interested in this association because we thought that if self-rated oral health is not an independent notion, it could be, to some extent, a reflection of self-rated general health, 
and quality of life particularly among some subgroups of the population. Therefore, this study aimed to assess the association among self-rated oral health, general health, and quality of life (QOL) in Korean older adults.

\section{Materials and Methods}

\section{Subjects}

A total of 3,840 households were surveyed, selected from 192 survey location. The overall participation rate was $82.8 \%$. All participants provided written informed consent for both the participation in the survey and use of the data for research purposes. Participants completed a health interview, health behavior survey, nutritional survey, and medical examination. A health interview includes a database of demographic characteristics (age, income, education, occupation, marital status, current smoking). This study analyzed 1,866 subjects aged 60 years or older who participated in KNHANES V-1 (January-December, 2010). Information regarding gender, age, marital status, education, smoking status was obtained from health behavior survey. Education was classified as less than elementary school, middle school, high school, and over college or University graduate. Occupation was divided into the current working and no current working. Marital status was classified by the presence/ absence of a spouse. Current Smoking was categorized as yes or no.

\section{Perceived Oral Health and General health}

The self-rated oral health was measured with the question "how do you think your oral health state is, considering your teeth and gums?" with a choice of five answers (very good, good, fair, poor, and very poor). Cronbach alpha for question was $0.65,0.66$, $0.65,0.67,0.69$, and 0.64 , respectively. Self-rated general health was measured with a question that "In general, would you rate your health?" and using single-item global ratings measured on 5-point Likert scales: 'poor,' 'fair,' 'good,' 'very good' and 'excellent.' The higher the scores indicate the more negative rated health.

\section{Quality of life}

The Korean version of the European quality of life questionnaire (EQ-5D) was used to evaluate the quality of life. The EQ-5D records the level of the self-reported problem according to five domains: mobility, self-care, usual daily activities, pain/discomfort, and anxiety/depression. Each domain is assessed based on a single question with three response level (no problem/ some problem/ extreme problems), and participants selected the statement that best described them. For logistic regression, "no problem" was considered as "no problem" with code " 0 " and "some problem," "extreme problems" were considered as "problem" with code "1."

\section{Statistical Analysis}

Data were analyzed by IBM SPSS/PC statistical program (version 23.0 for Windows; IBM SPSS, USA). Dichotomous variables are presented as percentage variables and analyzed with Chi-square test, and continuous variables are presented as a mean and standard deviation and were analyzed by independent t-test. Multivariate logistic regression analyses were conducted to analyze the association of the self-rated oral health with selfrated general health. After controlling for multivariate (age, gender, income, education, household income, smoking), the multivariate model gets odds ratios and 95\% C.I (Confidence Intervals) for all factors. P- Value<.05 was considered statistically significant for all statistical analyses.

\section{Results}

\section{General Characteristics of Study Population}

Table 1: General characteristics of study population.

\begin{tabular}{|c|c|c|c|}
\hline Variable & Category & $\mathrm{n}$ & $\%$ \\
\hline \multirow{2}{*}{ Gender } & Male & 836 & 44.8 \\
\hline & Female & 1030 & 55.2 \\
\hline \multirow{3}{*}{ Age(years) } & $60-70$ & 1091 & 58.5 \\
\hline & $70-80$ & 651 & 34.9 \\
\hline & $>80$ & 124 & 6.6 \\
\hline \multirow{4}{*}{ Marital status } & With spouse & 1323 & 71.3 \\
\hline & $\begin{array}{l}\text { With spouse, } \\
\text { separate }\end{array}$ & 18 & 1 \\
\hline & $\begin{array}{l}\text { Widow/ } \\
\text { Widower }\end{array}$ & 482 & 26 \\
\hline & Divorce & 33 & 1.8 \\
\hline \multirow{4}{*}{ Education } & $<$ Elementary & 1156 & 63.2 \\
\hline & Middles school & 256 & 14 \\
\hline & High school & 291 & 15.9 \\
\hline & $>$ College & 126 & 6.9 \\
\hline \multirow{4}{*}{ Family Income } & Low & 855 & 45.8 \\
\hline & Middle low & 464 & 24.9 \\
\hline & Middle high & 295 & 15.8 \\
\hline & High & 251 & 13.5 \\
\hline
\end{tabular}

Table 1 shows the general characteristics of study population. Among 1,866 study population, Over half of the sample was female (55.2\%), and the average age was 69.5 years. Almost a half of the participants were in $60-70$ years of age (58.5\%) followed by $34.9 \%$ of $70-80,6.6 \%$ of over 80 with no significant difference by gender. Most male participants (91.8\%) had a spouse however $42.4 \%$ of the female was the widow $(\mathrm{F}=33.12, \mathrm{p}<.001)$. There were significant disparities between male and female in education. Significantly more male than female were classified as higher education $(12.9 \%$ vs.2.0\%), but more females than males were classified as less than elementary education $(80.2 \%$ vs. $42.4 \%)(\mathrm{p}<.001)$. Almost half of the samples were low household income (45.8\%) (Table 1).

\section{Oral Health and Self-Rated Oral Health Status}

Participant's oral health status was shown in Table 2. More female than male had caries in permanent teeth $(90.2 \%$ vs. $86.2 \%)(\mathrm{F}=7.01, \mathrm{p}<.01)$ but there was no gender differences in a toothache within a year and the jaw pain. More female than male reported chewing difficulties ( $42.2 \%$ vs. $37.9 \%)(\mathrm{F}=3.44, \mathrm{p}<.05)$ but there were no gender differences in a problem in speaking Tables 2,3 shows the association between self-rated oral health and demographic characteristics. $45 \%$ of individuals rated their 
oral health as very good/good/ fair and only $55 \%$ as poor to a very pool. The average scores of self-rated oral health were 3.51 , and a Table 2: Oral health status in subjects. significantly higher proportion of participants were classified poor (45.92\%) and very poor (9.06\%).

\begin{tabular}{|c|c|c|c|c|c|c|}
\hline \multirow{2}{*}{ Variables } & \multirow{2}{*}{ Category } & \multicolumn{2}{|c|}{ Male } & \multicolumn{2}{|c|}{ Female } & \multirow{2}{*}{ Chi-square } \\
\hline & & $\mathbf{N}$ & $\%$ & $n$ & $\%$ & \\
\hline \multirow{2}{*}{$\begin{array}{c}\text { Caries in } \\
\text { permanent teeth }\end{array}$} & No & 115 & 13.8 & 101 & 9.8 & \multirow{2}{*}{$7.01^{* *}$} \\
\hline & Yes & 720 & 86.2 & 927 & 90.2 & \\
\hline \multirow{2}{*}{$\begin{array}{l}\text { Toothache within } \\
\text { a year }\end{array}$} & No & 623 & 74.3 & 745 & 72.2 & \multirow{2}{*}{0.651} \\
\hline & Yes & 196 & 23.4 & 256 & 24.8 & \\
\hline \multirow{2}{*}{ Jaw pain } & No & 801 & 95.5 & 974 & 94.4 & \multirow{2}{*}{0.731} \\
\hline & Yes & 17 & 2 & 27 & 2.6 & \\
\hline \multirow{2}{*}{$\begin{array}{l}\text { Chewing } \\
\text { difficulties }\end{array}$} & No & 517 & 62.1 & 595 & 57.8 & \multirow{2}{*}{$3.44^{*}$} \\
\hline & Yes & 316 & 37.9 & 434 & 42.2 & \\
\hline \multirow{5}{*}{$\begin{array}{l}\text { Problem in } \\
\text { speaking }\end{array}$} & Very discomfort & 10 & 1.2 & 15 & 1.5 & \multirow{5}{*}{7.093} \\
\hline & Discomfort & 112 & 13.4 & 163 & 15.8 & \\
\hline & Fair & 104 & 12.4 & 120 & 11.7 & \\
\hline & Problem & 315 & 37.7 & 399 & 38.7 & \\
\hline & Not at all & 287 & 34.3 & 330 & 32 & \\
\hline
\end{tabular}

Table 3: Perceived oral health by demographic characteristics.

\begin{tabular}{|c|c|c|c|c|}
\hline Variables & Category & $N$ & Mean \pm SD & $t / F$ \\
\hline \multirow{2}{*}{ Gender } & Male & 836 & $3.46 \pm 0.87$ & \multirow{2}{*}{$-0.24^{*}$} \\
\hline & Female & 1036 & $3.54 \pm 0.82$ & \\
\hline \multirow{3}{*}{ Age(years) } & $60-70$ & 1091 & $3.52 \pm 0.84$ & \multirow{3}{*}{0.192} \\
\hline & $70-80$ & 651 & $3.49 \pm 0.85$ & \\
\hline & $>80$ & 124 & $3.53 \pm 0.77$ & \\
\hline \multirow{4}{*}{ Education } & $<$ Elementary $^{a}$ & 1156 & $3.54 \pm 0.84$ & \multirow{4}{*}{$4.35^{*} \mathrm{a}, \mathrm{b}>\mathrm{d}$} \\
\hline & Middle $^{\mathrm{b}}$ & 256 & $3.52 \pm 0.84$ & \\
\hline & $\operatorname{High}^{c}$ & 291 & $3.48 \pm 0.84$ & \\
\hline & $>$ College $^{d}$ & 126 & $3.25 \pm 0.89$ & \\
\hline \multirow{5}{*}{ Self-rated Health } & Excellent $^{a}$ & 99 & $3.28 \pm 1.02$ & \multirow{5}{*}{$10.99^{* * *}$ a, b, c>d, e } \\
\hline & Good $^{b}$ & 470 & $3.41 \pm 0.89$ & \\
\hline & Fair $^{c}$ & 684 & $3.46 \pm 0.82$ & \\
\hline & Poor $^{d}$ & 465 & $3.63 \pm 0.79$ & \\
\hline & Very poor ${ }^{\mathrm{e}}$ & 144 & $3.80 \pm 0.76$ & \\
\hline
\end{tabular}

A significantly higher score of self-rated oral health in female than that of males $(\mathrm{t}=-0.24, \mathrm{p}<.05)$, which indicated that more female participants evaluate their oral health more negative. Lower educated participants have negatively rated their oral health than that of higher education ( $\mathrm{F}=4.35, \mathrm{p}<.05)$ (Table 3$)$. As for the general self-rated health, a significantly higher proportion of participants were classified poor (24.5\%) and very poor (7.6\%). There was a significant correlation between general self-rated health and selfrated oral health $(\mathrm{rho}=0.14, \mathrm{p}<.001)$. Participants who responded relatively better perceived general self-rated health had better score of self-rated oral health $(\mathrm{F}=10.99, \mathrm{p}<.001)$.The association among the self-rated oral health, activity limitation and EQ5D are shown Table 4. For those who have mobility limitation, the selfrated of oral health score was higher than those who without mobility limitation $(\mathrm{t}=-2.4, \mathrm{p}<.01)$.

The self-rated oral health was higher for those with moderate problem in mobility compared to those without mobility problem $(\mathrm{F}=10.18, \mathrm{p}<.01)$, for those with moderate problem in self-care (EQ$5 \mathrm{D}$ self-care) compared to those without problem $(\mathrm{F}=5.68, \mathrm{p}<.001)$, for those with moderate problem in usual activity compared to 
those without problem $(\mathrm{F}=8.11, \mathrm{p}<.01)$ and for those with moderate problem in pain/discomfort compared to those without problem $(F=8.88, p<.001)$. For those with the moderate and severe problem in anxiety/depression, the self-rated oral health was higher compared to those without a problem $(\mathrm{F}=13.52, \mathrm{p}<.001)$. The predictors perceived oral health is shown in Table 5. In a multivariate analysis

Table 4: Perceived oral health by activity limitation and EQ5D. adjusted for socioeconomic status, subjects who had less difficulty in chewing (OR: 0.15, 95\% CI: 0.13-0.20), better perceived health (OR: $0.47,95 \%$ CI: 0.25-0.90) and no depressive symptom (OR: $0.69,95 \%$ CI: 0.50-0.97) faced less perceived oral health difficulties than those who had chewing difficulties, worse perceived health and depressive symptom.

\begin{tabular}{|c|c|c|c|c|}
\hline Variables & Category & $N$ & Mean \pm SD & $t / F$ \\
\hline \multirow{2}{*}{ Activity limitation } & Yes & 436 & $3.63 \pm 0.81$ & \multirow{2}{*}{$-2.4^{* *}$} \\
\hline & No & 1397 & $3.47 \pm 0.85$ & \\
\hline \multirow{3}{*}{ EuroQOL Mobility } & No problem $^{\text {a }}$ & 1169 & $3.44 \pm 0.86$ & \multirow{3}{*}{$10.18^{* * *} \mathrm{a}<\mathrm{b}$} \\
\hline & Moderate problem ${ }^{\mathrm{b}}$ & 629 & $3.61 \pm 0.80$ & \\
\hline & Severe problem ${ }^{c}$ & 35 & $3.74 \pm 0.78$ & \\
\hline \multirow{3}{*}{ EuroQOL Self-care } & No problem a & 1169 & $3.48 \pm 0.85$ & \multirow{3}{*}{$5.68^{* *} \mathrm{a}<\mathrm{b}$} \\
\hline & Moderate problem ${ }^{\mathrm{b}}$ & 629 & $3.70 \pm 0.77$ & \\
\hline & Severe problem ${ }^{\mathrm{c}}$ & 35 & $3.40 \pm 0.74$ & \\
\hline \multirow{3}{*}{ EuroQOL Usual activity } & No problem ${ }^{\text {a }}$ & 1626 & $3.46 \pm 0.85$ & \multirow{3}{*}{$8.11^{* * *} \mathrm{a}<\mathrm{b}$} \\
\hline & Moderate problem ${ }^{\mathrm{b}}$ & 192 & $3.65 \pm 0.82$ & \\
\hline & Severe problem ${ }^{c}$ & 15 & $3.56 \pm 0.73$ & \\
\hline \multirow{3}{*}{ EuroQOL Pain/discomfort } & No problem ${ }^{\mathrm{a}}$ & 1107 & $3.44 \pm 0.85$ & \multirow{3}{*}{$8.8^{* * *}$} \\
\hline & Moderate problem ${ }^{\mathrm{b}}$ & 591 & $3.59 \pm 0.84$ & \\
\hline & Severe problem ${ }^{c}$ & 133 & $3.68 \pm 0.76$ & \\
\hline \multirow{3}{*}{$\begin{array}{l}\text { EuroQOL Anxiety/ } \\
\text { depression }\end{array}$} & No problem $^{\text {a }}$ & 1547 & $3.46 \pm 0.85$ & \multirow{3}{*}{$13.52^{* * *} a<b, c$} \\
\hline & Moderate problem ${ }^{\mathrm{b}}$ & 252 & $3.74 \pm 0.76$ & \\
\hline & Severe problem ${ }^{\mathrm{c}}$ & 32 & $3.78 \pm 0.75$ & \\
\hline
\end{tabular}

Table 5: Multiple logistic regression results of predictors perceived oral health.

\begin{tabular}{|c|c|c|c|c|c|c|c|}
\hline \multirow{2}{*}{ Variable } & \multirow{2}{*}{ Category } & \multicolumn{2}{|c|}{ Model 1} & \multicolumn{2}{|c|}{ Model 2} & \multicolumn{2}{|c|}{ Model 3} \\
\hline & & Odds Ratio & 95\% C.I. & Odds Ratio & 95\% C.I. & Odds Ratio & 95\% C.I. \\
\hline \multirow{3}{*}{ Age } & $60-70$ & 1 & & 1 & & 1 & \\
\hline & $70-80$ & 1.13 & $0.74-1.73$ & 1.28 & $0.80-2.04$ & 1.33 & $0.83-2.15$ \\
\hline & $>80$ & 1.00 & $0.65-1.53$ & 1.08 & $0.67-1.73$ & 1.10 & $0.68-1.77$ \\
\hline \multirow{2}{*}{ Gender } & Male & 1 & & 1 & & 1 & \\
\hline & Female & 1.03 & $0.82-1.29$ & 1.02 & $0.80-1.31$ & 1.09 & $0.66-1.74$ \\
\hline \multirow{4}{*}{ Education } & >College & & & & & & \\
\hline & $<$ Elementary & $1.80^{* *}$ & $1.19-2.71$ & $1.57^{*}$ & $1.00-2.45$ & 1.48 & $0.94-2.32$ \\
\hline & Middle & 1.54 & $0.98-2.40$ & 1.36 & $0.83-2.21$ & 1.34 & $0.82-2.19$ \\
\hline & High & 1.28 & $0.83-1.98$ & 1.34 & $0.84-2.14$ & 1.33 & $0.83-2.14$ \\
\hline \multirow[b]{2}{*}{ Marital status } & With Spouse & 1 & & 1 & & 1 & \\
\hline & $\begin{array}{l}\text { unmarried/ } \\
\text { divorced }\end{array}$ & 1.08 & $0.85-1.38$ & 1.10 & $0.84-1.44$ & 1.11 & $0.85-1.46$ \\
\hline $\begin{array}{c}\text { Caries in } \\
\text { permanent teeth }\end{array}$ & No & & & 0.87 & $0.68-1.11$ & 0.85 & $0.66-1.08$ \\
\hline Toothache & No & & & $0.77^{*}$ & $0.60-0.99$ & 0.79 & $0.61-1.01$ \\
\hline Jaw pain & No & & & 1.18 & $0.59-2.36$ & 1.25 & $0.62-2.51$ \\
\hline $\begin{array}{l}\text { Chewing } \\
\text { difficulties }\end{array}$ & No & & & $0.16^{* * *}$ & $0.13-0.20$ & $0.17^{* * *}$ & $0.13-0.21$ \\
\hline
\end{tabular}




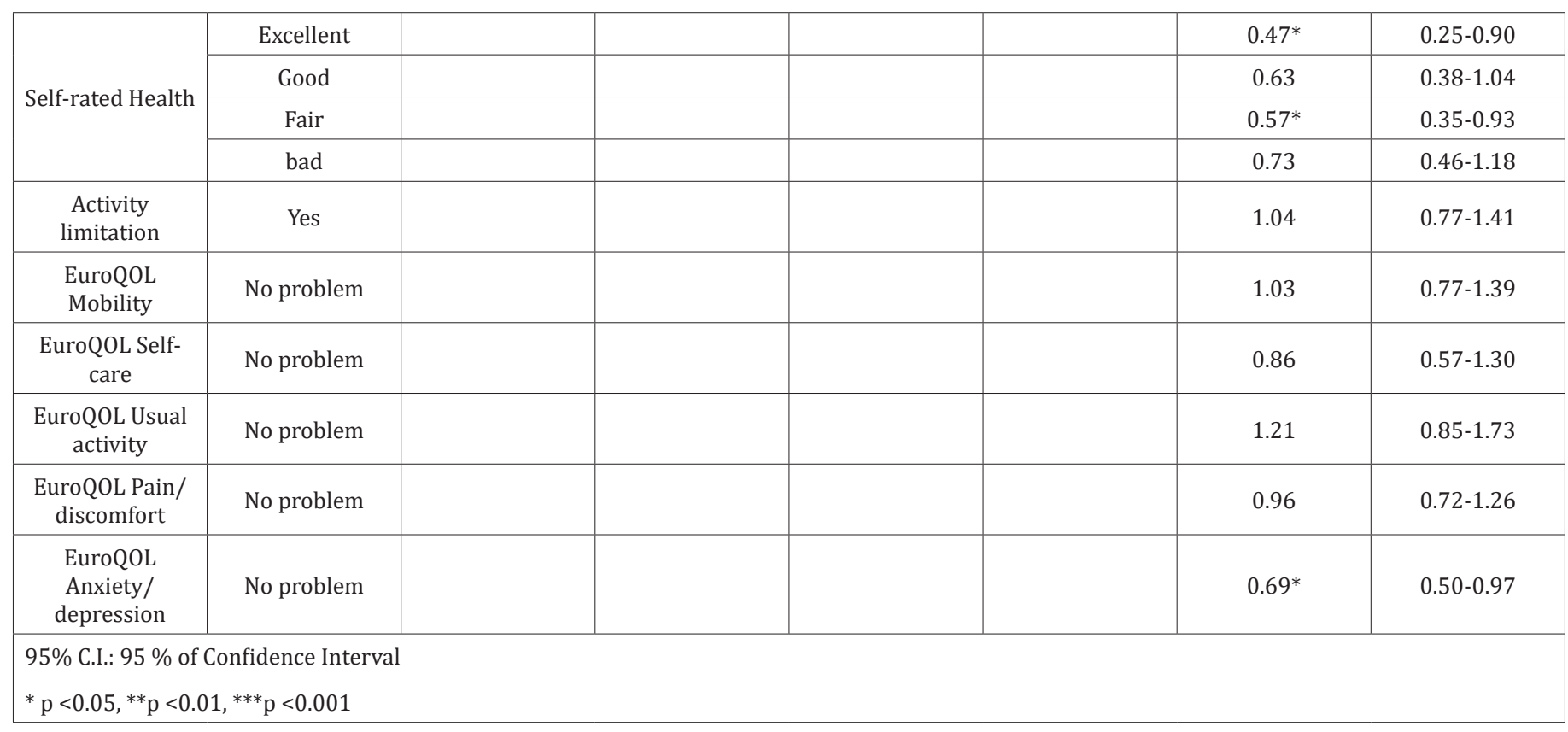

\section{Discussion}

In the present study, we investigated factors associated with self-rated oral health among community-dwelling Korean older adults. In the results, self-rated general health, mobility limitation, anxiety, and depression were associated with self-rated oral health, regardless of age, gender, household income, education, marital status and Caries in permanent teeth. As expected, the response of self-rated oral health in Korean elders was negative. Approximately one-half of elders (55\%) rated their oral health as poor to a very poor, which is within the range of the previous reports $[12,13]$. Self-rated oral health was significantly associated with caries in permanent teeth and chewing difficulties, and after controlling for covariates, chewing problem was only factors among oral problems that influence the self-rated oral health.

It is interesting that chewing problems was a substantial factor associated with poor self-rated oral health compared with other oral problems [14]. Reported one of the leading complaints of elders was not chewing well and masticatory function, which is an essential factor affecting the independently living older population, in particular. Also, the decline in chewing ability is related to functional frailty, lower QOL, and ADL $[10,15]$. There also was a contrast in the social inequalities profile of this impact in the sample under analysis. Previous research reported that subjects in lower education had higher oral health impact scores. In this study, elders of greater social inequalities in income and education distribution had negative self-rated oral health scores, which is consistent with previous research $[12,16,17]$. This study reported that mobility limitation is associated with self-rated oral health.

This result was consistent with [18] longitudinal study (2001) which showed that problems with mobility were associated with few teeth and chewing difficulties. This may indicate that a reverse causality can also be possible that is frailty can lead to poor oral function. Further, analysis of our data indicated that poorer perceived general health and poorer psychological well-being has lower self-rated oral health score. A better self-rated general health, mobility limitation and depression were associated with a better self-rated oral health. This findings indicated that a higher level of general health contribute to keep better oral hygiene and increase chance for socialization which may reduce anxiety and depression. As reported by [19], preventing mobility barriers may contribute to better general health, which has significant public health implication.

\section{Conclusion}

With an aging population there is a greater need for oral and dental care to maximizing successful aging. Based on the results of our study, general health is not only important as an independent effect on self-rated oral health, but it may operate synergistically with a higher level of mobility and anxiety/ depression as well. Therefore a comprehensive assessment of the oral health of the elders requires not only their oral status but also measure of functional capability as well as psychological condition.

\section{References}

1. Bloom B, Gift HC, Jack SS (1992) Dental services and oral health. Vital and health statistics. Series 10, Data from the National Health Survey (183): 1-95.

2. Adulyanon S, J Vourapukjaru, Sheiham A (1996) Oral impacts affecting daily performance in a low dental disease Thai population. Community dentistry and oral epidemiology 24(6): 385-389.

3. Sumio Akifusa, Izumi M, A Isobe, Mikiko Hironaka, Katsumi Hidaka (2017) Self-rated Masticatory Ability and Independent Life in Community Dwelling Elderly Populations. J Aging Geriatr Med 1(1).

4. Turner MD, JA Ship (2007) Dry mouth and its effects on the oral health of elderly people. The Journal of the American Dental Association 138: S15-S20.

5. Kandelman D, Petersen PE, Ueda H (2008) Oral health, general health, and quality of life in older people. Special care in dentistry 28(6): 224236.

6. Tickle M, R Craven, Worthington HV (1997) A comparison of the subjective oral health status of older adults from deprived and affluent communities. Community dentistry and oral epidemiology 25(3): 217222. 
7. Guo Y, HL Logan, Muller KE, Marks JG, Riley JL (2014) Health literacy: a pathway to better oral health. American Journal of Public Health 104(7): e85-e91.

8. Locker D, M Clarke, Payne B (2000) Self-perceived oral health status, psychological well-being, and life satisfaction in an older adult population. Journal of dental research 79(4): 970-975.

9. Castrejón-Pérez RC, SA Borges-Yáñez, Irigoyen-Camacho ME, CruzHervert LP (2017) Negative impact of oral health conditions on oral health related quality of life of community dwelling elders in Mexico city, a population based study. Geriatrics \& gerontology international 17(5): 744-752.

10. Hoeksema A, S Spoorenberg, Peters LL, Meijer H, Raghoebar GM, et al (2017) Elderly with remaining teeth report less frailty and better quality of life than edentulous elderly: a cross-sectional study. Oral diseases 23(4): 526-536.

11. Benyamini Y, H Leventhal, Leventhal EA (2004) Self-rated oral health as an independent predictor of self-rated general health, self-esteem and life satisfaction. Social science \& medicine 59(5): 1109-1116.

12. Matthias RE, Atchison KA, Lubben JE, Jong F, Schweitzer SO (1995) Factors Affecting Self-ratings of Oral Health. Journal of Public Health Dentistry 55(4): 197-204.

13. Ohara Y, H Hirano, Watanabe Y, Obuchi S, Yoshida H, et al. (2015) Factors associated with self-rated oral health among community-dwelling older
Japanese: A cross-sectional study. Geriatrics \& gerontology international 15(6): 755-761

14. Locker D, D Matear, Stephens M, Lawrence H, Payne B (2001) Comparison of the GOHAI and OHIP-14 as measures of the oral health-related quality of life of the elderly. Community dentistry and oral epidemiology 29(5): 373-381.

15. Miura H, M Kariyasu, Yamasaki K, Arai Y, Sumi Y (2005) Relationship between general health status and the change in chewing ability: a longitudinal study of the frail elderly in Japan over a 3-year period. Gerodontology 22(4): 200-205.

16. Martins AM, Barreto SM, Pordeus IA (2008) Factors associated to self perceived need of dental care among Brazilian elderly. Revista de SaúdePública 42(3): 487-496.

17. Mesas AE, De Andrade SM, Cabrera MAS (2008) Factors associated with negative self-perception of oral health among elderly people in a Brazilian community. Gerontology 25(1): 49-56.

18. Avlund K, P Holm-Pedersen, Schroll M (2001) Functional ability and oral health among older people: a longitudinal study from age 75 to 80 . Journal of the American Geriatrics Society 49(7): 954-962.

19. Iwasaki M, A Yoshihara, Sato N, Sato M, Minagawa K, et al. (2018) A 5 -year longitudinal study of association of maximum bite force with development of frailty in community-dwelling older adults. Journal of oral rehabilitation 45(1): 17-24.

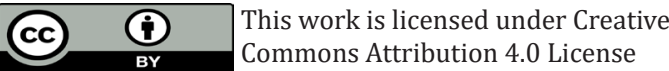

Submission Link: https://biomedres.us/submit-manuscript.php

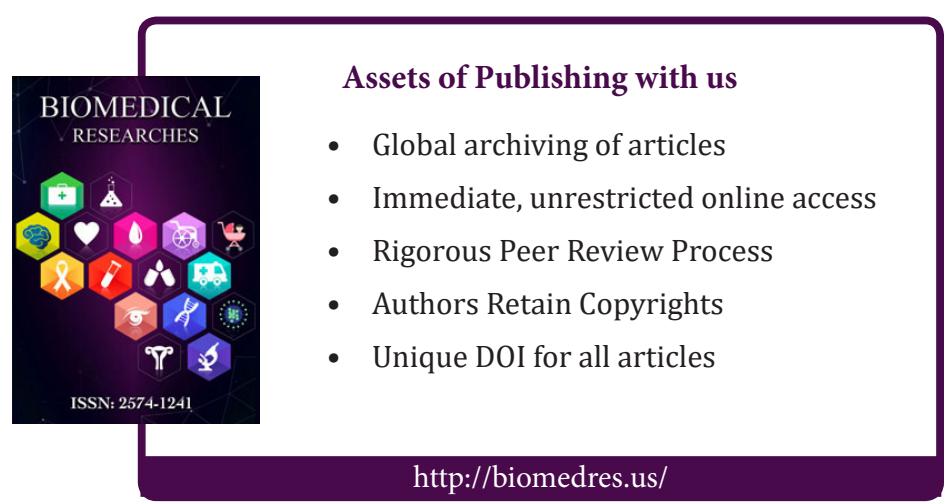

